\title{
MÚSICA, BRINCADEIRA E AFETO: POSSÍVEIS FACILITADORES DA LINGUAGEM DE CRIANÇAS COM AUTISMO
}

\author{
MÚSICA, BRINCADEIRA Y AFECTO: POSIBLES FACILITADORES \\ DEL LENGUAJE DE NIÑOS CON AUTISMO
}

\begin{abstract}
MUSIC, JOKE AND AFFECT: POSSIBLE FACILITATORS OF CHILDREN'S LANGUAGE WITH AUTISM
\end{abstract}

EMILENe Gomes MonteIRO ${ }^{1}$

${ }^{1}$ Universidade Federal do Espírito Santo (UFES), Espírito Santos/ES-Brasil

\begin{abstract}
Resumo Este artigo versa sobre um estudo bibliográfico, com base no referencial da Psicologia Histórico-Cultural, a respeito da relação entre música, brincadeira e afeto. Considera-se a música e a brincadeira, permeadas por afetos, como possíveis meios potencializadores do desenvolvimento de crianças com autismo, facilitando desse modo sua linguagem. A mediação pedagógica e o possível estímulo psicológico, afetivo e social, propiciado por esse contato, se apresentam como potentes meios para esse propósito. Tal movimento se propõe como caminho alternativo às apropriações dessa criança na aquisição e ampliação da linguagem e também aos processos inclusivos no contexto educacional.
\end{abstract}

Palavras-chave: Música; Brincadeira; Autismo.

ABSTRaCr This article is a bibliographic study about the relationship between music, play and affection, considering music and play, permeated by affections, as possible means of potentiating the development of children with autism, thus facilitating their language. The possible psychological, affective and social stimulus, provided by this contact appears to be powerful in this regard. The role of pedagogical mediation is a contributor to this process. This movement is proposed as an alternative way to the appropriations of this child in the acquisition and expansion of language and to the inclusive processes in the educational context. Based on the reference of Historical-Cultural Psychology, this study was constituted to analyze this theme.

Keywords: Music; Childhood; Autism. 
RESUMEN Este artículo trata de un estudio bibliográfico sobre la relación entre música, broma y afecto, considerando la música y la broma, impregnadas de afectos, como posibles medios potenciadores del desarrollo de niños con autismo, de esta manera, facilitando su lenguaje. El posible estímulo psicológico, afectivo y social, propiciado por este contacto, se presenta como potente a este propósito. El papel de la mediación pedagógica se constituye contribuyente a este proceso. Tal movimiento se propone como camino alternativo a las apropiaciones de este niño en la adquisición y ampliación del lenguaje y también a los procesos inclusivos en el contexto educativo. Con base en el referencial de la Psicología Histórico-Cultural, este estudio se constituyó para el análisis de esta temática.

Palabras Clave: Música; Broma; Autismo.

\section{INTRODUÇÃo}

De acordo com Bréscia (2003), a música se constitui como uma linguagem universal, tendo participado da história da humanidade desde as primeiras civilizações. Denota uma forma de linguagem facilmente aceita pelo indivíduo. Ela estimula, sensibiliza, interfere e possivelmente propicia a sua compreensão do mundo que o cerca. Brito (2003) pontuou: "[...] o modo como as crianças percebem, aprendem e se relacionam com os sons, no tempo-espaço, revela o modo com percebem, apreendem e se relacionam com o mundo que vêm explorando e descobrindo a cada dia" (BRITO, 2003, p. 41).

Nesse aspecto, a música pode contribuir significativamente para o desenvolvimento infantil, e, dialogando com as particularidades e especificidades da criança, pode colaborar com a potencialização de sua linguagem. Assim, observa-se que o contato musical pode viabilizar à criança com autismo o envolvimento e/ou condição propícios aos avanços da linguagem, visando desenvolvimento em sua comunicação em diferenciados âmbitos.

Para Brandalise (2013), são necessários programas terapêuticos e educacionais voltados às pessoas com transtorno do espectro do autismo (TEA), visando potencializá-las em seus recursos próprios e especificidades. Nesse viés, de acordo com o autor, uma das modalidades terapêuticas muito utilizadas com esses sujeitos é a musicoterapia, que possibilita o estímulo e a melhora deles em diferentes campos de desenvolvimento.

$\mathrm{O}$ autor ainda destaca que, conforme pesquisas já realizadas, se observa existir considerável e relevante interesse, como também investimentos, direcionados aos estudos sobre o uso da música, da musicoterapia e do trabalho clínico dedicados aos indivíduos com transtorno do espectro do autismo, propiciando êxitos e ganhos na potencialização da linguagem desses sujeitos.

Brandalise (2013) ainda indicou que, na atuação da musicoterapia direcionada aos sujeitos diagnosticados com autismo, se utilizam com maior incidência três de seus métodos: a) o receptivo, em que os sujeitos recebem a música por meio da escuta, podendo interagir com a experiência verbalmente ou utilizando outra modalidade de expressão; b) o criativo, em que há a possibilidade de criarem novas contribuições à música escutada, desse modo incentivando improvisações musicais como uma resposta natural a essa vivência, e c) recriativo, em que o sujeito é incentivado a recriar situações vivenciadas e ressignificá-las por meio do contato com a música. 
Observa-se que há uma possível interface entre a música e a psicologia e a atuação desses campos nos processos referentes à linguagem. Na educação, a música tem sido mencionada como instrumento pedagógico de grande importância para o desenvolvimento psicológico, motor e afetivo. Nota-se que a presença da música na esfera da aprendizagem potencializa a percepção sensorial, incentiva a memória e a inteligência, por conceber um universo que viabiliza a expressão de sentimentos, ideias, valores culturais; e ainda possibilita a comunicação do indivíduo consigo mesmo e com o meio no qual se encontra inserido.

De acordo com Oliveira et al. (2014), a música viabiliza a verbalização, respeitando as especificidades e capacidades de cada sujeito, de modo que lhe é possível vivenciar tal possibilidade. Segundo os autores, para a criança com TEA não é sempre fácil falar de si e do que está sentindo, mas, por meio da música, é propiciado a ela revelar seus sentimentos, dessa forma transmitindo suas emoções, por intermédio de uma canção, uma dança ou um instrumento.

A análise apresentada neste trabalho se situa no contexto da educação (especial), mas com considerações coadjuvantes da área da musicoterapia, por se tratar de criança com autismo.

Vigotski (1984) procurou elaborar os alicerces de um novo pensamento visando avançar na psicologia por meio de uma abordagem que conseguisse retratar e elucidar as funções psicológicas superiores, e a conciliação entre o instrumento e o signo na atividade psicológica. Segundo o autor, funções alusivas à consciência - como intenção, planejamento, ações voluntárias, deliberadas e o pensamento - são originadas nos contextos de aprendizagem, considerados como processos mediados culturalmente.

Segundo Góes (1991), essas experiências, propiciadas pela mediação pedagógica de um professor, viabilizam esse manejo, pois, para Vigotski, o sujeito produz suas maneiras de ação e sua consciência com base nas relações sociais, e neste entendimento norteia seus caminhos à suplantação da dicotomia social/individual.

Para Kozulin (1994), uma das temáticas centrais na teoria de Vigotski diz respeito aos denominados processos mentais superiores, os quais são funções da atividade mediada e se constituem na maneira do funcionamento psicológico tipicamente humano, como a memória voluntária, a capacidade de planejamento, a atenção seletiva. São, por conseguinte, decursos intencionais e voluntários. O preceito de mediação semiótica no funcionamento psíquico já preserva essa premissa, pois afirma que meio da intersubjetividade o acesso à realidade se efetiva por intermédio da significação e pela mediação do outro (GÓES, 1993, 1995).

Para Fiore-Correia e Lampreia (2012), o contato com o outro, viabilizando conexão afetiva, se constitui substancial para o desenvolvimento infantil, devendo ser considerado nas intervenções educativas com crianças autistas. Assim, a mediação sensível, presente, atenta e criativa, pode propiciar o estabelecimento de um vínculo afetivo, incentivando a socialização e interação dessas crianças, oportunizando a vivência de aspectos lúdicos próprios do universo infantil, o que possibilita uma condição facilitadora e potencial para a sua comunicação.

Nesse âmbito, o abarque da linguagem de conferir à realidade uma existência simbólica é salientado à sua máxima potência, especificamente no que tange ao enfoque proposto. Metodologicamente, o presente artigo foi produzido embasado em uma revisão bibliográfica, que contemplou estudos já realizados acerca dessa temática. 
Segundo Bréscia (2003), a musicalização é um meio para a construção do conhecimento, que possui o objetivo de despertar e desenvolver o gosto musical, possibilitando o desenvolvimento da percepção sonora, da sensibilidade, da criatividade, do senso rítmico, do prazer de ouvir música, da imaginação, da socialização e da afetividade, também contribuindo para uma efetiva consciência corporal e de movimentação apontando possibilidades de intervenções no campo educacional.

No decurso do desenvolvimento, a linguagem se desenvolve por meio de diferenciados modos relacionais e práticas sociais elaboradas historicamente e, entre essas ações, se encontra a brincadeira, notadamente a que se refere à primeira infância. Vigotski salientou a relevância do papel da brincadeira no desenvolvimento infantil, especificamente no que tange à criança pequena. Desse modo, postulou:

Na brincadeira, a criança está sempre acima da média da sua idade, acima de
seu comportamento cotidiano; na brincadeira, é como se a criança estivesse
numa altura equivalente a uma cabeça acima da sua própria altura. A brinca-
deira em forma condensada contém em si, como na mágica de uma lente de
aumento, todas as tendências do desenvolvimento; ela parece tentar dar um
salto acima do seu comportamento comum (VIGOTSKI 2008, p. 35 ).

Segundo o autor, a brincadeira possibilita à criança vivenciar diversas e potencializadoras situações, que na vida real possivelmente não seriam tão fáceis e acessíveis de serem vividas por ela, no modo e na intensidade que o são no período em que brinca. Nesse viés, a criança com autismo, quando participa de uma brincadeira e/ou é incentivada a brincar, pode vivenciar situações que lhe serão potencializadoras em seu desenvolvimento. Os possíveis afetos que constituem esse momento oportunizam a ela experienciar vivências, compondo saberes e fazeres que lhe propiciam desenvolver-se em diferentes esferas.

Dessa forma, Santos e Batista (2016) indicam a necessidade e urgência de se estudar a relação entre afetividade, autismo e educação, assim como investigar quais são os possíveis indivíduos com os quais sujeitos com TEA estabelecem vinculação afetiva e quais os modos como esses vínculos ocorrem, visto que comumente se apresenta dificuldade em seu estabelecimento devido aos consideráveis comprometimentos da dimensão social dessas crianças.

Vigotski (1983) pontua que as funções psíquicas superiores são produzidas no desenvolvimento social e não apenas e propriamente no plano biológico, todavia, este propicia o alicerce para o desenvolvimento cultural dos pequenos: “[...] a cultura dá origem a formas de conduta, modifica a atividade das funções psíquicas, edifica novos níveis no sistema do comportamento humano no transcorrer do desenvolvimento" (VIGOTSKI, 1983, p. 34). Desse modo, a cultura exerce influência sobre o nosso substrato biológico, produzindo alterações no status das predisposições instintivas, viabilizando novas possibilidades às funções elementares e possibilitando novas funções psíquicas.

Assim, o contato social propiciador do desenvolvimento cultural se constitui significativamente potente para os avanços da linguagem infantil. A criança com autismo é capaz de socializar e, se incentivada, pode relacionar-se afetivamente com os outros, ainda que essa relação apresente contornos diferenciados. A afetividade possível a esse movimento pode potencializar consideravelmente esse processo. 
Neste estudo, analisaram-se os seguintes tópicos:

a) A música inserida na brincadeira por meio de canções infantis, possivelmente permeadas por afetos, e as contribuições dessa dinâmica em contexto educacional para os processos de desenvolvimento de crianças com autismo;

b) O contato com a música, por meio do canto e da escuta de canções infantis e cantigas de roda, como propiciador do estímulo da oralidade e da possível percepção de si e do outro, nesses pequenos.

\section{O AUTISMo}

O presente estudo traz como parte de seu enfoque o autismo, descrito em 1908 pelo psiquiatra suíço Eugen Bleuer, que utiliza pela primeira vez o termo para descrever um conjunto de sintomas que remetiam à esquizofrenia. $\mathrm{O}$ termo possui raízes no grego "autos", que remonta ao eu. Após algumas décadas, no ano de 1943, Leo Kanner, psiquiatra austríaco radicado nos Estados Unidos e diretor de psiquiatria infantil do Johns Hopkins Hospital, publica a obra "Distúrbios Autísticos do Contato Afetivo", ampliando o que se conhecia até aquele momento. Leo Kanner contextualizou as observações feitas no desenvolvimento, assim como ressaltou a predominância dos déficits de relacionamento social e a preponderância de comportamentos incomuns e/ou estereotipados.

No ano de 1945, Hans Asperger, psiquiatra e pesquisador austríaco, publicou o artigo "A psicopatia autista na infância". Realizou observações sobre um padrão de comportamento e habilidades, que ocorria mais acentuadamente em meninos. Notou que eles apresentavam déficits sociais considerados graves, como falta de empatia, conversação unilateral, baixa capacidade de ter amizades, intenso foco em um único assunto e movimentos desorganizados. A Síndrome de Asperger recebeu esse nome após alguns anos, em 1952. Na primeira edição do Manual Diagnóstico e Estatístico de Doenças Mentais, DSM-I (Diagnostic and Statistical Manual of Mental Disorders - DSM-I), sintomas semelhantes eram classificados como um subgrupo da esquizofrenia infantil.

O autismo ainda não era considerado como um diagnóstico único. Entre as décadas de 1950 e 1960, houve um caos nesse contexto, oriundo da dúvida sobre a possível natureza do autismo e sua etimologia. Acreditava-se que a causa da ocorrência de autismo eram pais emocionalmente não responsivos a seus filhos. Mães não calorosas, consideradas "mães geladeira", carregavam a culpa dessa problemática, devido à ausência do oferecimento de seu aconchego. Nesse período, Leo Kanner cunhou o termo; contudo, o psicanalista Bruno Bettelheim o tornou mais popular. Em 1965, uma jovem norte-americana chamada Temple Grandin nasceu com autismo, considerado, naquele contexto, Síndrome de Asperger. Em sua trajetória, criou a "Máquina do Abraço". Esse feito foi embasado em estudos sobre as práticas de abate para animais em fazendas e seus projetos e técnicas foram significativos nesse segmento, sendo utilizados em vários países.

No ano de 1978, Michael Rutter classifica o autismo e sugere sua delimitação embasado em quatro critérios, a saber: o primeiro, atraso e desvio sociais e não apenas deficiência intelectual; o segundo, problemas de comunicação, novamente não somente em associação de função de deficiência intelectual; terceiro, comportamentos percebidos como incomuns, 
como movimentos estereotipados e os considerados maneirismos, e quarto, o início das manifestações dos possíveis sintomas antes dos 30 anos de idade.

Com a classificação do autismo, Michel Rutter estabelece um marco divisor no entendimento dessa síndrome. Em 1980, a classificação de Rutter, associada à ascendente produção de estudos sobre o autismo, prepondera a respeito da determinação da definição no DSM-III. Houve o reconhecimento dessa proposição e, por conseguinte, inserção em outra classe de alterações: Transtornos Invasivos do Desenvolvimento - TDIs. Essa terminologia reflete a afetação de múltiplas áreas de funcionamento do cérebro, possivelmente ocasionadas pelo autismo e as situações a ele referentes. Nesse contexto, delimitadas na Classificação Internacional de Doenças - CID-10.

Em 1981, uma psiquiatra inglesa chamada Lorna-Wing avultou o conceito de autismo como um espectro de condições e, posteriormente, adotou o termo Síndrome de Asperger, aludindo à pesquisa de Hans Asperger. Seu estudo revolucionou o modo como o autismo era entendido e suas contribuições foram significativas em muitos países.

No ano de 1988, um psicólogo da Universidade da Califórnia Los Angeles - UCLA, chamado Ivar Lovaas, publicava um estudo considerado relevante, que apresentava a importância da terapia comportamental para crianças com autismo, o que trouxe novas esperanças aos pais desses pequenos. O DSM substituiu a denominação de autismo infantil por transtornos do autismo e associou uma nova listagem de critérios diagnósticos. Em 1998, novos critérios de análise para o autismo foram considerados em um estudo internacional multicêntrico, que incluiu diversos casos, analisados por mais de 100 avaliadores clínicos.

Ainda no ano de 1998, o cientista inglês Andrew Wakefield publica um artigo, afirmando que algumas vacinas, entre elas a tríplice ( $\mathrm{mmr}$ - sarampo, catapora e rubéola) causariam autismo. Em pesquisas realizadas nos últimos anos, comprovou-se que a vinculação da vacina ao autismo não possui base científica. Em 2007, a ONU estabeleceu o dia 2 de abril como o Dia Mundial da Conscientização do Autismo.

No decorrer do ano de 2013, os subtipos dos transtornos do espectro do autismo são eliminados. Com o lançamento da quinta edição do DSM, os sujeitos são diagnosticados em um único espectro, com diferentes níveis de gravidade. As crianças com diagnóstico de autismo possivelmente apresentam comportamentos pré-linguísticos, como apontar ou guiar outra pessoa pela mão, para realizar alguma ação. Somado a esse fato, alguns pequenos podem manifestar-se por meio de problemas de comportamento, como agressão, autoagressão ou birras, com o objetivo de se relacionar.

Em 2014, uma série de pesquisas, em um amplo estudo realizado na Suécia, comprovou que fatores ambientais são tão relevantes quanto a genética, como possível causa do autismo. Oliveira e Padilha (2016) pontuaram:

\footnotetext{
No caso de crianças com autismo, avanços no funcionamento mental e nos processos de autorregulação ocorrerão na medida em que o contexto em que vivem lhes possibilitar experiências enriquecedoras de aprendizagem, assentadas em processos de interação e de interlocução significativos para elas (OLIVEIRA; PADILHA, 2016, p. 189).
}

Para Martins (2011), é possível que os pequenos que apresentam desenvolvimento típico utilizem também alguns modos de ações pré-linguísticas, como vocalizar, ou ainda 
movimentos corporais típicos com o objetivo de se comunicar, durante o desenvolvimento precoce e anterior ao aparecimento de uma comunicação mais simbólica, composta com gestos formais e fala, em seu desenvolvimento.

O autismo, de acordo com Schwartzman (2011, p. 37), é considerado um "transtorno do desenvolvimento de causas neurobiológicas definido de acordo com critérios eminentemente clínicos". Desse modo, se configuram as três principais áreas comprometidas que constituem a considerada tríade autística, a saber: déficits na interação social, déficits na comunicação verbal e não verbal e a presença de padrões de comportamento, interesses ou atividades restritas, repetitivos e estereotipados. Essa alteração traz como consequência aos sujeitos com diagnóstico de autismo possíveis comprometimentos, que ainda podem se apresentar em outras disfunções, tais como ecolalia, comprometimento intelectual, dificuldades de socialização e, por conseguinte, o atraso na aprendizagem. Podem interferir diretamente no processo de apropriação da linguagem, possivelmente dificultando-o.

Nesse contexto, nos surge a questão: Como lidar com esse possível déficit, especificamente referindo-se às crianças com diagnóstico de autismo, sem infantilizá-los em demasia ou limitar suas potencialidades? Nota-se que estimular é necessário, contudo, em se tratando de crianças com a síndrome, a escolha do estímulo se torna mais delicada. A estratégia necessita ser eficaz, contudo, deve também ser sensível e acolhedora, no sentido de promoção do devido desenvolvimento das potencialidades dessas crianças. Assim, observa-se que "[... a relação com o outro e a linguagem adquirem um papel primordial, permitindo as condições necessárias ao desenvolvimento de formas superiores de pensamento e ao controle da própria conduta por parte do sujeito" (OLIVEIRA; PADILHA, 2016, p. 189).

\section{APropriação da LINGUAGEM}

De acordo com Albano (1990), a criança necessita de quatro condições básicas e indispensáveis para o desenvolvimento da linguagem. A primeira é a presença de um interesse subjetivo na criança, qual seja, uma disposição de brincar. Para ele, crianças abrutalhadas ou emocionalmente desordenadas apresentam consideráveis dificuldades ao desenvolvimento da fala. A segunda é a existência de ao menos um sistema sensório-motor pleno (audiovisual ou viso-motor). A terceira é a possível inserção em um meio, onde a linguagem seja constituinte de rotinas significativas. Para ele, crianças negligenciadas ou severamente institucionalizadas não aprendem a falar. A quarta e última seria a presença de uma língua minimamente autocentrada, que possua alguns mecanismos gramaticais, pontuando a própria organização, de modo que se proceder à descoberta da sua estrutura eficientemente, direcionando-se mais ou menos determinadamente.

Nesse viés, ressaltando a discussão sobre a criança com autismo, ela não apresentaria a primeira condição mencionada, a do interesse subjetivo em interagir com o outro. Neste aspecto, a música pode auxiliar essa criança, viabilizando o contato com este outro, por meio da escuta e do canto de canções, de cantigas de roda, da vivência de atividades e/ou brincadeiras musicais em grupo, entre outras possibilidades. Além de incentivar a oralidade e a escuta, a música propicia relevante fonte de estímulos e sensações para a criança, evoca sentimentos, a imaginação criadora, a sensibilidade e a atenção, potencializando o 
âmbito afetivo e psíquico da criança. A música auxilia as manifestações de pensamentos, de percepções, a aprendizagem de palavras, apreensão de conceitos, seja no momento em que se canta uma letra, ou quando se ouve uma melodia.

A linguagem se caracteriza por seu caráter essencial ao desenvolvimento de todo e qualquer sujeito, possibilitando a compreensão do mundo e a ação neste. Dessa maneira, se constitui o modo mais comum de encontros, desencontros e confrontos de posições, pois é por ela que posicionamentos se tornam publicizados, assim viabilizando a compreensão e propagação de saberes.

Nesse ínterim, o decurso da concepção de um conhecimento sistematizado é relevante tanto por si como também pela influência que exerce sobre o saber cotidiano. Este, "ao situar-se entre o conceito científico e seu objeto, adquire toda uma série de novas relações com outros conceitos e se modifica ele próprio em sua relação com o objeto" (VIGOTSKI, 1993, p. 259). Os estudos de Vigotski $(1984,1987,1989)$ atribuem à linguagem e à interação social um papel fundante na constituição do sujeito e denotam relevância cabal no desenvolvimento humano.

A criança, vista como sujeito, se constitui em uma gênese social, permeada pela cultura, e, por conseguinte, é sempre o outro que outorga sentido à fala e ações desta em um processo semioticamente mediado, carregado de símbolos e significações. Nesse âmbito, Padilha (2017) considerou:

Conhecimentos que as crianças aprendem no dia a dia e que vão constituindo seus modos de ser, de pensar, de agir, de querer, de sentir. Suas interações com os adultos, com crianças mais velhas e com produtos culturais vão dirigindo a linguagem, a imitação, a percepção, a atenção, a memória, a imaginação, os valores, os hábitos. Os significados das palavras e das ações vão sendo apropriados nas relações sociais concretas da vida. Esses significados evoluem, transformam-se. Ao aprenderem a repetir palavras e ações no início da vida, as crianças vão, aos poucos, aprendendo novos significados para as mesmas palavras e ações (PADILHA, 2017, p. 13).

Ainda de acordo com Vigotski (2009), o percurso de desenvolvimento dos conceitos solicita o desenvolvimento de funções como a atenção arbitrária, a memória lógica, a abstração, a comparação e a discriminação. "Vigotski relaciona desenvolvimento das funções superiores ou culturais com elaboração conceitual e desenvolvimento do pensamento e da linguagem" (PADILHA, 2017, p. 13).

Para Vigotski (2000), o possível desenvolvimento do conhecimento científico e, ainda, o amadurecimento das funções psicológicas superiores, acontecem por intermédio da colaboração sistemática, nesse enfoque entre o professor e a criança. Assim, a linguagem se compõe na relação mediada do professor para com os pequenos. Na concepção de Vigotski (2000, p. 33), todo homem se constitui como humano por meio das relações que estabelece com os outros sujeitos.

Para Padilha (2017), "a palavra do outro ajuda o sujeito a formar conceitos, que constituem o significado das palavras, das ações, das emoções. Por último, a elaboração conceitual não é um processo individual" (PADILHA, 2017, p. 18). 
Pino (1995) ressaltou que a linguagem abarca a esfera da significação e, nesse âmbito, a função do signo. A significação acontece por meio da interação com o outro, que o constitui nessa relação. Segundo Vigotski (2000), o sujeito não é apenas ser de ação, mas também é interativo, pois apreende conhecimentos e se constitui a partir de relações intra e interpessoais. "Funções psicológicas de nível mais elaborado se desenvolvem, como a atenção mediada, a percepção e a memória, entre outras" (OLIVEIRA et al., 2016, p. 80).

Dessa maneira, se configura um processo que trilha do plano social, composto por relações consideradas interpessoais, e transita para o plano individual, composto por relações consideradas intrapessoais. Em suma, compreende-se que é na troca com outros sujeitos e consigo mesmo que se vão internalizando conhecimentos, funções sociais e papéis que propiciam a composição de conhecimentos e da própria consciência. Nesse viés, se configura o contexto propiciador para o desenvolvimento da linguagem dessas crianças.

\section{MÚSiCA, BRINCADEIRA, AFETO E O AUTISMO NO CONTEXTO DA EDUCAÇÃo}

A intervenção da música como facilitadora dos processos de aprendizagem de crianças com autismo, propiciada pelo estímulo musical que permite o contato com os aspectos psicológicos, emocionais e sociais, incentivando a sensibilidade, a ludicidade e a criatividade, tem sido objeto de estudo de alguns autores.

Nogueira (2006) menciona que os brinquedos musicais integram a vida da criança desde muito cedo e afirma que é por meio dos acalantos, das parlendas, das brincadeiras ritmadas entre mãe e bebê que se estabelecem as primeiras experiências lúdico-musicais da vida humana. E, no aspecto da formação humana, Lisardo (2009) aponta que a música traz contribuições significativas, no que se refere aos sentimentos, propiciando sensações, movimentos, percepções, afetos e, desse modo, incentiva e viabiliza o contato com o outro, agente potente que se apresenta como viabilizador da inserção social da criança com autismo. Assim pontuou:

\footnotetext{
A música que nos transmite sensações, emoção ao ouvir, cantar ou dançar, a música que nos aproxima das vibrações ou da escuta musical é a mesma que dialoga com o corpo, que evoca a linguagem, cria fantasias e possibilita a toda pessoa descobrir-se a si própria e ao mesmo tempo se revelando ao outro, inserindo-se no convívio social (LISARDO, 2009).
}

Segundo Brito (2003), a educação musical propõe-se à formação integral das crianças como um todo, abarcando todos os seus aspectos vivenciais enquanto sujeito, não se restringindo apenas à formação de possíveis músicos. Desse modo, para Brito, o contato com os eventos sonoros propicia enriquecedoras possibilidades de interações com o entorno, assim contribuindo significativamente para a formação da consciência humana. Assim, pontuou:

A percepção, a discriminação e a interpretação de eventos sonoros, geradores de interações com o entorno, têm grande importância no que diz respeito à formação e permanente transformação da consciência de espaço e tempo, um dos aspectos prioritários da consciência humana (BRITO, 2003, p. 19). 
Especificamente no que tange às crianças com autismo, Sampaio, Loureiro e Gomes (2015) ressaltam que a literatura acerca dessa temática salienta e discorre sobre uma intensa e vigorosa relação entre os sujeitos com tal diagnóstico e a música. Destacam o âmbito não-verbal da música como o principal meio de engajamento do sujeito com autismo e seu interlocutor, seja no momento da apresentação de uma música estritamente instrumental, ou ainda em instantes em que haja um texto narrado ou cantado nesse movimento musical.

Para Nascimento et al. (2015), as atividades que envolvem música propiciam às crianças diagnosticadas com autismo ganhos e avanços no desenvolvimento notavelmente observados, destacando-se a socialização e a apreensão de comandos.

Santos (2015) apontou que a emoção que perpassa a experiência musical compartilhada propicia registros no cérebro, e estes podem abrir novas vias e possibilidades onde os sujeitos com autismo podem transitar e seguir. A autora salienta acreditar que a emoção abarcada na experiência musical, compartilhada entre os sujeitos com autismo, pode ser manifesta e reproduzida em outros contextos onde eles atuam, como em seu cotidiano, na escola, em meio a sua família, entre outros cenários possíveis.

No Referencial Curricular Nacional para a Educação Infantil (BRASIL, 1998, p. 45), se encontra a menção acerca da importância da música enquanto meio de comunicação, em diferenciados âmbitos. Constitui-se em uma linguagem que possibilita ao sujeito exprimir-se, em diversos aspectos, e se configura como uma das formas relevantes da expressão humana. Assim:

\begin{abstract}
A música é a linguagem que se traduz em formas sonoras capazes de expressar e comunicar sensações, sentimentos e pensamentos, por meio da organização e relacionamento expressivo entre o som e o silêncio. A integração entre os aspectos sensíveis, afetivos, estéticos e cognitivos, assim como a promoção de interação e comunicação social, conferem caráter significativo à linguagem musical. É uma das formas importantes de expressão humana, o que por si só justifica sua presença no contexto da educação, de um modo geral, e na educação infantil, particularmente (BRASIL, 1998, p. 45).
\end{abstract}

A música pode ser inserida no contexto educacional por diferenciados meios, e uma dessas vias se constitui na brincadeira. De acordo com Suplino (2007), estudos que aludem à brincadeira da criança com autismo destacam a sua potência como ferramenta para a inclusão desta, na medida em que pode propiciar maneiras diferenciadas de interação entre ela e os outros pequenos. Ressalte-se que o professor mediador, nesse contexto, deve organizar o conteúdo das brincadeiras de forma sistematizada; suas ações necessitam ser compreensíveis, intencionais e significativas.

Vigotski (1989) destaca que, ao abordar as crianças com deficiência, devemos observá-las e também ao seu desenvolvimento, embasando-se nas mesmas leis que norteiam o desenvolvimento das demais crianças, fundamentos que também se referem às crianças com autismo. Estes requerem a mediação do outro no processo de inserção no mundo da cultura, com o objetivo de que o seu desenvolvimento cultural se estabeleça. Igualmente é o brincar das crianças com autismo - tal emergência e enriquecimento possui estreita relação com as possibilidades de mediação, que encontram em seu ambiente. Desse modo, "[...] acerca do papel da brincadeira no desenvolvimento infantil, considerando a hipótese 
de que a criança com autismo estaria sujeita às mesmas leis do desenvolvimento que as demais crianças, [...] ainda que seu percurso apresente certas peculiaridades" (OLIVEIRA; PADILHA, 2016, p. 200). Nesse âmbito, Pinto e Góes (2006) pontuaram:

\begin{abstract}
Assim, ao brincar, a criança apóia-se no vivido, mas não só reproduz; emancipa-se das situações concretas e age de maneira imaginativa, assimilando suas experiências, ao mesmo tempo em que as retoma de forma criativa. Ou seja, a brincadeira tem base na vivência, mas não se constitui em simples reiteração da realidade conhecida. Nela, a criança usa objetos substitutivos, encena, dramatiza situações e personagens, num processo de re-significação (PINTO; GÓES, 2006, p. 14).
\end{abstract}

Segundo Góes (2002), diante da condição de deficiência, faz-se necessário propiciar formas culturais singulares, que permitam mobilizar as forças compensatórias e explorar caminhos alternativos de desenvolvimento, que requerem recursos especiais. A música oferece possível contribuição para a constituição desse sujeito, como totalidade. Através da música, a criança pode ser conduzida ao contato com o universo letrado e o lúdico. Os possíveis afetos emergentes no âmbito da brincadeira propiciados pelo contexto lúdico acessado, associados ao contato com o outro, se apresentam como elementos potentes na constituição e desenvolvimento dessas crianças. Desse modo, observa-se que, "[..] na relação estabelecida com o outro, mais do que um sentido único, o que se destaca é uma multiplicidade de sentidos a respeito desse outro, acompanhada de ressonâncias afetivas que podem ser variadas e até contraditórias" (OLIVEIRA; GEBARA, 2010 p. 373). Brito (2003) pontuou:

As cantigas de ninar, as canções de roda, as parlendas e todo tipo de jogo musical têm grande importância... Os momentos de troca e a comunicação sonoro-musicais favorecem o desenvolvimento afetivo e cognitivo, bem como a criação de vínculos fortes tanto com os adultos quanto com a música (BRITO, 2003, p. 35).

De acordo com Tassoni (2011), Vigotski defendeu que a natureza dos afetos se altera, constituindo-se em novos e diferenciados modos de sentir. A inserção da música a esse movimento, seja por meio de cantigas de roda ou por canções do repertório infantil, pode contribuir na potencialização das crianças com autismo, no viés da possível sensibilização dos pequenos. Os afetos, ao serem tocados pela intervenção musical, podem facilitar a relação com o outro, viabilizando assim os processos de linguagem. Ao cantar as canções já mencionadas, a criança é incentivada a emitir sons, a articular e pronunciar palavras e também a conhecê-las. Possivelmente, explora sensações, seus sentimentos são estimulados e, por conseguinte, o gosto pela vivência desse contexto possivelmente lhe é propiciado. Observa-se que essa dinâmica pode contribuir significativamente aos decursos educacionais.

A música, na educação infantil, mantém forte ligação com o brincar. Em algumas línguas, como no inglês (to play) e no francês (jouer), por exemplo, usa-se o mesmo verbo para indicar tanto as ações de brincar quanto as de tocar música. Em todas as culturas as crianças brincam com a música. Jogos e brinquedos 
musicais são transmitidos por tradição oral, persistindo nas sociedades urbanas nas quais a força da cultura de massas é muito intensa, pois é fonte de vivências e desenvolvimento expressivo musical (BRASIL, 1998, p. 71).

Com base em pesquisas já realizadas sobre as possíveis contribuições da música na educação infantil, nota-se a relevância dessa ferramenta por viabilizar o desenvolvimento de diversas habilidades, entre elas a oralidade, escuta, percepção, socialização, criatividade, ludicidade, o movimento corporal, entre outras.

Vinculado a esse aspecto, segundo Leontiev (1988), o brincar não se configura uma ação instintiva e sim constituída no contato com os outros e com as práticas sociais; é um campo que pode ser compreendido sob o lento e progressivo domínio dos objetos, os quais a criança utiliza como brinquedo, e da ação no plano simbólico, em um viés de satisfação de suas necessidades.

Assim, observa-se que a brincadeira propicia uma zona de desenvolvimento iminente na criança. Oliveira (1995) esclarece que essa zona de desenvolvimento se configura como domínio psicológico em permanente transformação, reporta-se ao trajeto de amadurecimento de suas funções - isto é, ações que nesse momento a criança realiza com o auxílio do outro, possivelmente também conseguirá, amanhã, sozinha realizar.

Nesse âmbito, a música possibilita relevante contribuição aos processos de desenvolvimento infantil e consequente apropriação da linguagem, estimulando o desenvolvimento psicológico e educacional das crianças. E, associada à brincadeira, promove a socialização destas, possivelmente otimizando relações na sala de aula. Ambas incentivam a criatividade e o desenvolvimento da coordenação motora, encorajam a expressão corporal e a linguagem oral e viabilizam a integração cultural desses pequenos. Especificamente no que se refere ao contato musical, o ato de cantar, assobiar, murmurar e/ou emitir sons propicia elementos sonoros e também afetivos e, por meio da intensidade do som, da inflexão da voz e da entonação, viabiliza o contato com o outro, se apresentando relevante para o progresso da criança com autismo, no sentido de seu desenvolvimento em vários campos, como o linguístico, auditivo, emocional, psicológico e de apropriação da linguagem.

\section{CONSIDERAÇões FINAIS}

O presente estudo discutiu a atuação da música, inserida no contexto da brincadeira sendo permeada por afetos e, assim, se constituindo como possíveis meios potencializadores do desenvolvimento de crianças com autismo, desse modo facilitando sua linguagem.

Nesse viés, foi proposta a análise da possibilidade de que a música nos afeta emocionalmente, e esse fato favorece as funções psicológicas superiores, no que tange à aprendizagem. Partindo do pressuposto de que o sujeito pode se desenvolver mediante estímulos diversos e criativos que lhe propiciem a liberdade consigo mesmo, a investigação problematizou que a música, na forma de cantigas de roda, como também na forma presente no cancioneiro infantil, ambas modalidades inseridas na brincadeira, notavelmente potencializam esse movimento.

A conexão entre o desenvolvimento, o brincar e a mediação são consideradas relevantes para a produção de novas aprendizagens e consequente apropriação da linguagem. 
Observa-se uma significativa vinculação entre as atividades lúdicas e as funções psíquicas superiores. Desse modo, é possível compreender sua importância sócio-psíquica para a educação infantil.

O estudo permite dizer que a música realiza significativas contribuições nos seguintes campos da vivência da criança com autismo: socialização, aquisição de novas palavras e assim consequente apropriação da linguagem, capacidade inventiva, expressividade, incentivo à sensibilidade e à ludicidade, coordenação motora, percepção sonora, como também o desenvolver do raciocínio lógico. Há ainda de se ressaltar a contribuição que a música pode propiciar ao caráter humano do sujeito, uma vez que o contato musical lhe possibilita o sentido estético, a apreciação sensorial, o tanger dos afetos, a criatividade e a sensibilidade. Dessa maneira, compreende-se que a atividade musical pode viabilizar a consciência humana e a liberdade de transformar-se a si mesmo. Pino (2006) salientou:

\begin{abstract}
No seu sentido mais genérico, a atividade é uma característica geral do universo dos seres vivos, dentro do qual se situa o ser humano. As diferentes formas de atividade existentes nesse universo revelam a diversidade das formas de vida que constituem as diferentes espécies. Isso nos permite pensar que a espécie humana, como qualquer outra, caracteriza-se por um determinado tipo de atividade, o qual revela sua forma peculiar de ser e de viver. Fundada nas características gerais da atividade dos seres vivos, esta atividade adquire uma forma nova especificamente humana, em que o adjetivo "humana" qualifica a atividade remetendo-nos ao campo da auto-determinação, da liberdade e da consciência. De maneira mais específica, a atividade a que me refiro é a atividade criadora, aquela que permite aos seres humanos agir sobre a natureza e transformá-la em função de objetivos próprios e, pelo mesmo ato, transformarem-se a si mesmos (PINO, 2006, p. 49).
\end{abstract}

Desse modo, se apresentam notáveis as contribuições da música aos processos de desenvolvimento da criança com autismo. Assim, considerando o ingresso cada vez maior de crianças com necessidades especiais nas escolas regulares (BRASIL, 2006), surge a preocupação e o interesse em aprofundar as questões relevantes que envolvam as intervenções educacionais no processo de inclusão das crianças com diagnóstico de autismo no contexto educacional brasileiro. A música se constitui um bom caminho para contribuir com essa questão.

Ainda nesse âmbito, o presente estudo também possibilitou a compreensão de que, pela via da mediação do outro, a criança com autismo manifesta diversas potencialidades, entre as quais o brincar de faz de conta, que, com orientação por meio de uma mediação planejada, sistematizada e intencional, pode incentivar a imaginar, criar e assumir papéis que viabilizam e potencializam seu desenvolvimento, em várias esferas.

Tal estudo se configura como um instrumento científico de relevância social. A promoção do movimento aqui analisado, sua atuação como meio potencializador do desenvolvimento de crianças com autismo, em vários campos, salientada a facilitação dos processos de linguagem, interação social e bem-estar das crianças a ele submetido, se configurou como o objetivo deste trabalho.

Ao buscar embasamento em artigos e estudos relacionados ao tema proposto, enfocou-se a música inserida na brincadeira, permeada por afetos, como potencializadora 
dos recursos desenvolvimentistas da criança, assim viabilizando o desenvolvimento da linguagem. E especificamente referente às crianças com autismo, destaca-se a utilização desse manejo de modo intencional, planejado e sistematizado, fazendo deste um caminho alternativo, possivelmente facilitador do processo de inclusão dessa criança no contexto educacional.

Desse modo, constatou-se a contribuição da música, inserida na brincadeira, possibilitando a vivência de afetos e, como elementos presentes na realidade infantil viabilizam as funções psicológicas superiores, favorecendo o desenvolvimento das crianças com autismo em vários âmbitos, assim constituindo o objetivo final deste estudo. Observamos que há uma correlação entre as variáveis mencionadas neste estudo, todavia, percebemos serem necessárias mais análises aprofundadas a respeito do tema.

\section{REFERÊNCIAS}

ALBANO, E. C. Da fala à linguagem: tocando de ouvido. São Paulo: Martins Fontes, 1990.

BRANDALISE, A. Musicoterapia aplicada à pessoa com Transtorno do Espectro do Autismo (TEA): uma revisão sistemática. Revista Brasileira de Musicoterapia, n. 15, p. 28-42, ano XV, 2013.

BRASIL. Lei n. 11.769, de 18 de agosto de 2008. Altera a Lei nº. 9.394, de 20 de dezembro de 1996. Lei de Diretrizes e Bases da Educação, para dispor sobre a obrigatoriedade do ensino da música na educação básica. Brasília, DF, 2008. Disponível em: http://www. planalto.gov.br/ccivil_03/_Ato2007-2010/2008/lei/L11769.htm. Acesso em: 19 jul. 2020.

BRASIL. Ministério da Educação e do Desporto. Secretaria de Educação Fundamental. Referencial curricular nacional para a educação infantil. Brasília: MEC/SEF, 1998.

BRASIL. Secretaria de Educação Especial. Evolução da Educação Especial no Brasil. Dados do Censo Escolar 2006 (MEC/INEP). Disponível em: http://portal.mec.gov.br/seesp/ arquivos/pdf/dadosed.pdf . Acesso em: 15 jul. 2020.

BRÉSCIA, V. P. Educação musical: bases psicológicas e ação preventiva. Campinas: Átomo, 2003.

BRITO, Teca de Alencar. Música na educação infantil: propostas para a formação integral da criança. São Paulo: Petrópolis, 2003.

FIORE-CORREIA, O.; LAMPREIA, C. A conexão afetiva nas intervenções desenvolvimentistas para crianças autistas. Revista Psicologia: ciência e profissão, v. 32, n. 4, p. 926-941, 2012.

GÓES, M. C. R. A construção de conhecimentos: examinando o papel do outro nos processos de significação. Temas de Psicologia, 2, 1995, p. 23-29. 
GÓES, M. C. R. A natureza social do desenvolvimento psicológico. In: Cadernos CEDES 24 - Pensamento e linguagem, 2. ed. Campinas: Papirus, 1991, p. 17-24.

GÓES, M. C. R Os modos de participação do outro nos processos de significação na criança. Temas de Psicologia, 1, 1993, p. 1-5.

GÓES, M. C. R. Relações entre desenvolvimento humano, deficiência e educação: contribuições da abordagem histórico-cultural. In: OLIVEIRA, M. K.; SOUZA, D. T. R.; REGO, T. C. Psicologia, educação e as temáticas da vida contemporânea. São Paulo: Moderna, 2002, p. 95-114.

KANNER, L. Os distúrbios autísticos de contato afetivo. In: ROCHA, P. (Org.). Autismos. São Paulo: Escuta, 1997 (p. 11-170) (Original publicado, em 1943).

KOZULIN, A. La psicologia de Vygotsky. Madri: Alianza, 1994, cap. 4, p. 111-47.

LEONTIEV, A. N. Os princípios psicológicos da brincadeira pré-escolar. In: VIGOTSKI, L. S.; LURIA, A. R.; LEONTIEV, A. N. Linguagem, desenvolvimento e aprendizagem, São Paulo: Ícone, 1988, p. 119-142.

LISARDO, Hernany. Música e inclusão social: construindo novos paradigmas. Betim: Funarbe, 2009.

MARTINS, A. L. F. Avaliação dos distúrbios da linguagem no autismo infantil. Dissertação (Mestrado em Medicina) - Universidade da Beira Interior, Covilhã, Portugal, 2011.

NASCIMENTO, P. S. et al. Comportamentos de Crianças do Espectro do Autismo com seus Pares no Contexto de Educação Musical. Rev. bras. educ. espec., Marília, v. 21, n. 1, p. 93-110, mar. 2015. Disponível em: http://www.scielo.br/scielo.php?script=sci_arttext\&pid=S1413-65382015000100093\&lng=en\&nrm=iso. Acesso em: 27 mar. 2020.

NOGUEIRA, M. A. Música e educação infantil: possibilidades de trabalho na perspectiva de uma pedagogia da infância. Disponível em: http://www.anped.org.br/28/textos/gt07/ gt07213int.rtf. Acesso em: 15 jul. 2020.

OLIVEIRA, I. M.; GEBARA, A. Interação, afeto e construção de sentidos entre crianças na brinquedoteca. Educação e Pesquisa, São Paulo, v. 36, n. 1, p. 373-387, 2010.

OLIVEIRA I. M., PADILHA A. M. L. Crianças com autismo na brinquedoteca: modos de interação e de inserção nas práticas culturais. Revista Comunicações, 23 (3), p. 185-202, 2016.

OLIVEIRA, I. M.; VICTOR, S. L.; CHICON, J. F. Montando um quebra-cabeça: a criança com autismo, o brinquedo e o outro. Revista COCAR, Belém, v. 10, n. 20, p. 73-96, ago./ dez. 2016. 
OLIVEIRA MF, OSELAME GB, NEVES EB, OLIVEIRA EM. Musicoterapia como ferramenta terapêutica no setor da saúde: uma revisão sistemática. Rev Univ Vale Rio Verde, 2014 [acesso em: 2020 jul. 19]; 12 (2), p. 871-878. Disponível em: http://periodicos.unincor.br/index.php/revistaunincor/article/view/1739.

OLIVEIRA, M. K. Vygotsky: aprendizado e desenvolvimento um processo sócio-histórico, 3. ed. São Paulo: Scipione, 1995.

PADILHA, A. M. L. Desenvolvimento Psíquico e Elaboração Conceitual por Alunos com Deficiência Intelectual na Educação Escolar. Ver. Bras. Ed. Esp., Marília, v. 23, n. 1, p. 9-20, jan./mar. 2017.

PINO, A. As marcas do humano: às origens da constituição cultural da criança na perspectiva de Lev S. Vigotski. São Paulo: Cortez, 2005.

PINO, A. A produção imaginária e a formação do sentido estético. Reflexões úteis para uma educação humana. Pro-Posições, Campinas, v. 17, n. 2(50), p. 47-69, ago. 2006.

PINTO, G. U.; GÓES, M. C. Deficiência Mental, Imaginação e Mediação Social: um Estudo sobre o Brincar. Rev. bras. educ. espec., jan./abr. 2006, v. 12, n.1, p. 11-28.

SAMPAIO, R. T.; LOUREIRO, C. M. V.; GOMES, C. M. A. A Musicoterapia e o Transtorno do Espectro do Autismo: uma abordagem informada pelas neurociências para a prática clínica. Per musi, Belo Horizonte, n. 32, p. 137-170, dez. 2015. Disponível em: http://www. scielo.br/scielo.php?script=sci_arttext\&pid=S1517=75992015000200137-\&lng=en\&nrmiso. Acesso em: 27 mar. 2020.

SANTOS, C. E. C. "Desenvolvimento de habilidades musicais em crianças autistas": um projeto de extensão, pesquisa e ensino. Revista Nupeart, 14 (14), p. 74-90, 2015.

SANTOS, V. BATISTA, M. Autismo, educação e afetividade: um diálogo a partir das contribuições de Vygotsky, Wallon e Bowlby. Anais, 3, CODENU, v. 1, 2016.

SCHWARTZMAN, José Salomão. Transtornos do Espectro do Autismo: Conceitos e generalidades. In: SCHWARTZMAN, José Salomão; ARAÚJO, Ceres Alves (Org.). Transtornos do Espectro do Autismo. São Paulo: Memnon Edições Científica, 2011, p. 37-42.

SUPLINO, M. H. F. O. Retratos e imagens das vivências inclusivas de dois alunos com autismo em classes regulares, 2007, 169s. Tese (Doutorado em Educação) - Programa de Pós-Graduação em Educação, Universidade do Estado do Rio de Janeiro, Rio de Janeiro, 2007.

TASSONI, E. C. M.; LEITE, S. A. S. Um estudo sobre emoções e sentimentos na aprendizagem escolar. Comunicações. Piracicaba, Ano 18, n. 2, p. 79-91, jul./dez. 2011.

VIGOTSKI, L. S. A brincadeira e o seu papel no desenvolvimento psíquico da criança. 
Revista Virtual de Gestão de Iniciativas Sociais, Rio de Janeiro, n. 8, p. 23-36, jun. 2008. (Trad. Zóia Prestes.)

VIGOTSKI, L. S. Manuscrito de 1929. Educação e Sociedade: revista de ciência da educação, Campinas, SP, v. 21, n. 71, p. 21-44, jul. 2000.

VYGOTSKI, L. S. A formação social da mente. São Paulo: Martins Fontes, 1984.

VYGOTSKI, L. S. Fundamentos da Defectologia. Obras Completas. Tomo 5. Playa, Ciudad de La Habana: Editorial Puelo y Educación, 1989.

VYGOTSKI, L. S. Imaginação e criação na infância. São Paulo: Ática, 2009.

VYGOTSKI, L. S. Obras escogidas: problemas del desarrollo de la psique, v. 3. Madri: Visor, 1983.

VYGOTSKI, L. S. Pensamento e linguagem. São Paulo: Martins Fontes, 1987.

\section{Dados da Autora:}

\section{EMILENE Gomes Monteiro}

Mestre em Educação, pela Universidade Federal do Espírito Santos/ES-Brasil. emilenegmonteiro@hotmail.com

Submetido em: 13-7-2018

Aceito em: 6-8-2020 